International Research Journal of Engineering, IT \& Scientific Research
Available online at https://sloap.org/journals/index.php/irjeis/
Vol. 4 No. 6, November 2018, pages: $1 \sim 9$
ISSN: 2454-2261
https://sloap.org/journals/index.php/irjeis/article/view/330

\title{
Experimental Method to Determine the Isosteres of Adsorbent/Adsorption Pairs of Adsorption Cooling Systems
}

\author{
Bayardo Bohorquez Escobar ${ }^{\text {a }}$ \\ Reinaldo Guillen Gordin ${ }^{b}$
}

\section{Article history:}

Received: 20 July 2018

Accepted: 30 September 2018

Published: 10 October 2018

\section{Keywords:}

Adsorbate;

Adsorbent;

Adsorption;

Isosteras;

Renewable energy;

\begin{abstract}
A qualitative experimental method is presented to determine the amount of adsorbate, which is adsorbed by different adsorbents. It is explained how to determine the isosteres in conditions of saturation, for the levels of temperature and pressure with which usually operates in the systems of cooling by adsorption with the use of solar energy. The method allows obtaining the $\mathrm{kg}$ of refrigerant per $\mathrm{kg}$ of adsorbent to perform the design of cooling systems of a certain refrigeration capacity, from the mass of refrigerant that is absorbed and desorbed. The accuracy of the method is influenced by the quality of the instruments used in the experiments.
\end{abstract}

2454-2261 ${ }^{\circledR}$ Copyright 2018. The Author. This is an open-access article under the CC BY-SA license (https://creativecommons.org/licenses/by-sa/4.0/) All rights reserved.

\section{Author correspondence:}

Bayardo Bohorquez Escobar,

Ph.D. student, Center for Energy and Refrigeration Studies, School of Mechanical Engineering, Universidad de Oriente, Cuba. Senior Lecturer, Faculty of Technical Education for Development, Catholic University of Santiago de Guayaquil. Ecuador.

Email address: bbohorquez52@hotmail.es.

\section{Introduction}

About $30 \%$ of the energy generated worldwide is used for the operation of thermodynamic systems used for air conditioning, heating and cooling (Shmroukh, A. N., Ali, A. H. H., Abel-Rahman, A. K., \& Ookwara, S. (2015). The adsorption cooling systems currently acquire a singular importance because of their possibility to use renewable energy sources (ERP) and environmentally friendly refrigerant/adsorbent pairs, which make it a clean technology (González, M. I., Rodríguez, L. R., \& Lucio, J. H. (2009).

These work systems have been used in very limited quantities, so their presence in the market is almost exclusive (Brossard L F., Guillén R J., Vázquez L C. (1993). Despite studies carried out by different authors, these systems have not been generalized as those of vapor compression, this is influenced by the low operating coefficients that are obtained, however, being able to use it with FRE, it is necessary to carry out research that complements the existing ones, to achieve the development of sustainable alternative technologies in the production of low temperatures for air

a Professor, Technical Faculty of the Catholic University of Santiago de Guayaquil, Ecuador

${ }^{\mathrm{b}}$ Titular Professor of Mechanical Engineering, Universidad de Oriente, Santiago de Cuba, Cuba 
conditioning and refrigeration purposes. Among the substances most commonly used as adsorbents, there is a wide variety of activated carbons, zeolite and silica, while a wide range can currently be selected as an absorbate, including methanol, water, ammonia, hydrocarbons, hydrofluorocarbons and others (Sadhikh, M., \& Skaria, J. J. (2016).

For the design of the adsorption cooling systems, it is necessary to have the constant concentration diagram called isosteres that are expressed in a natural logarithm graph of the pressure $(\ln \mathrm{P})$ versus the inverse negative of the temperature $(-1 / \mathrm{T})$ with the isosteres of the adsorbent / adsorbate pair, as shown in figure 1, being able to determine the pressure, temperature and concentration levels and trace the Adsorption Cooling Cycle (CEA), to define the constructive and operational characteristics of the installation that is want so that each pair presents different values of the preferred parameters. For this reason, in this work a method is established using equipment, instruments, and resources available in conventional laboratories where the CEA diagram can be drawn up, for different selected pairs and in this way to be able to compare and select the most suitable pairs for different applications (Rodriguez, A. C. Z., Gamez, M. R., \& Faure, L. G., 2018).

\section{Materials and Methods}

To describe the method, the CEA is represented, with the isotypes represented by the inclined lines in figure 1 .

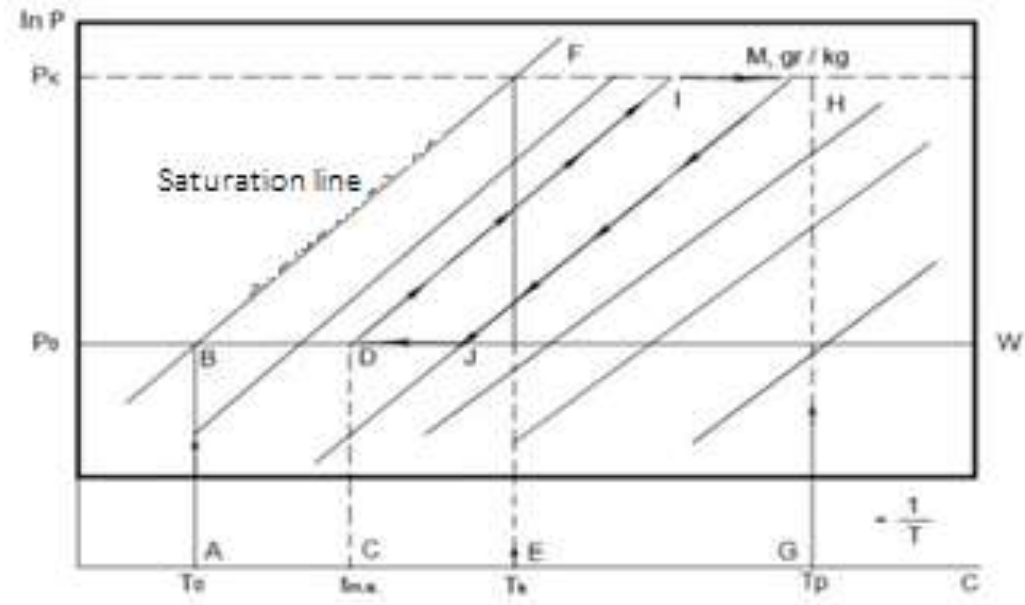

Figure 1. CEA with the isotypes represented by the inclined lines

To start the method, the example must be considered when it is intended when making ice, the boiling temperature of the absorber (coolant) must be below $0{ }^{\circ} \mathrm{C}$. It is possible to assume $-3{ }^{\circ} \mathrm{C}$., with this temperature a vertical $\mathrm{AB}$ is drawn. Point $\mathrm{B}$ is in the saturation line corresponding to the set temperature and defines the evaporator pressure.

The horizontal B $-\mathrm{W}$ then drew.

Here it is necessary to know:

The value of the temperature of the room where the heat of adsorption is given (tma),

The value of the temperature at which the condensation heat is transferred (tk) y

The value of the maximum temperature that the adsorbent torque will reach during heating (tp)

From room temperature the vertical CD is drawn, to define the point $\mathrm{D}$ of figure 1 , which represents the end of the adsorption of the adsorbate by the adsorbent.

The tk is the condensation temperature and is determined by the equation:

$$
t_{k}=t_{m a}+\Delta t
$$


Donde:

$t_{m a} \rightarrow$ Temperature of the medium taken to extract the heat of condensation

$\Delta \mathrm{t} \rightarrow$ Difference of condensation temperature in the case of air can be between $10^{\circ} \mathrm{C}$ and $12^{\circ} \mathrm{C}=10 \% 12{ }^{\circ} \mathrm{C}$, if it is water, it is considered between $5^{\circ} \mathrm{C}$ and $7^{\circ} \mathrm{C}$ (Brossard L F., Guillén R J., Vázquez L C. (1993).

With tk you can draw the line EF, point $\mathrm{F}$ where it is in the saturation line and define the condensation pressure. The maximum temperature (tp) that the torque can reach depends on the heat source, for example for solar energy with the flat collector is around $95^{\circ} \mathrm{C}$. By defining (tP) it can plot the vertical GH. Point $\mathrm{H}$ determines the end of the desorption. The cycle is formed by DIH J.

The adsorbent reaches the maximum concentration at point D. It is then heated without expelling adsorbate (sensible heat) to point $\mathrm{I}$, in the IH section it releases adsorbate, which condenses to point $\mathrm{H}$ in where it does not expel more adsorbalo. The adsorbent begins to cool from $\mathrm{H}$ to $\mathrm{J}$, where it begins to adsorb to point $\mathrm{D}$ (Allouhi, A., Kousksou, T., Jamil, A., Agrouaz, Y., Bouhal, T., Saidur, R., \& Benbassou, A. (2016).

Condensation occurs from I to $\mathrm{H}$, cooling occurs from $\mathrm{J}$ to $\mathrm{D}$.

The calculations performed are:

$M_{D}-M_{H} \rightarrow$ are the $g r$ grams adsorbate/ $\mathrm{kg} / \mathrm{kg}$ adsorbent-adsorbed and desorbed during the cycle causing the cooling required (Sataralli A. et al., 2012).

So the heat $\mathrm{Q}(\mathrm{kJ})$ that must be extracted from the medium to be cooled is calculated by equation (2).

$$
\frac{Q}{r}=G
$$

$\mathrm{r} \rightarrow$ is the latent heat of the adsorbalo $(\mathrm{kJ} / \mathrm{kg})$

$\mathrm{G} \rightarrow$ the amount of adsorbate that intervenes in the cycle $(\mathrm{kg})$

With the equation (3) the amount of absorbent $\mathrm{Z}$ can be determined $(\mathrm{kg})$.

$$
Z=\frac{G}{M_{D}-M_{H}}
$$

The method of calculation that is exposed is based on the plot of the isosteric, the parameter that needs to be known as:

$$
M_{D}-M_{H} \rightarrow \text { adsorbate gr / adsorbent } \mathrm{Kg}
$$

Based on this proceed as follows:

In an Erlenmeyer of approximately $100 \mathrm{ml}$ capacity with rubber cover, inlet tube and glass valve as shown in figure 2 , dead weight is determined $(\mathrm{Pm})$ in grams.

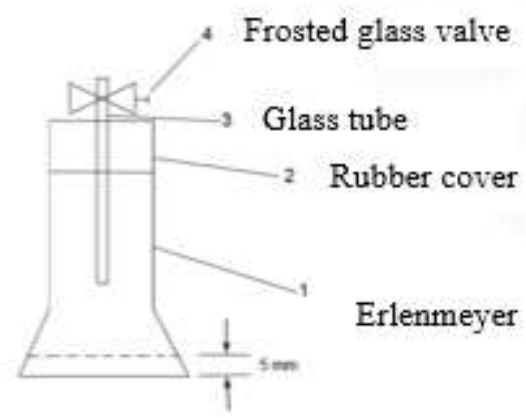

Figure 2. Test for determining the dead weight

\footnotetext{
Escobar, B. B., \& Gordin, R. G. (2018). Experimental method to determine the isosteres of adsorbent/adsorption pairs of adsorption cooling systems. International Research Journal of Engineering,

IT \& Scientific Research, 4(6), 1-9. https://doi.org/10.21744/irjeis.v4n6.330
} 
In this Erlenmeyer previously determined its dead weight $(\mathrm{Pm})$ of the set, the adsorbent is introduced in such amount that it takes approximately $5 \mathrm{~mm}$ from the bottom as indicated in figure 2 , it is placed in an oven at $120{ }^{\circ} \mathrm{C} 150{ }^{\circ} \mathrm{C}$ during 8 to 10 hours so that all the moisture that may contain is removed.

The Erlenmeyer must be placed in the oven without the valve stopper, after the indicated time before being removed from the oven, the stopper is placed and the whole set is weighed on a precision balance $(0.01 \mathrm{gr})$ determining the total weight $\left(\mathrm{P}_{\mathrm{t}}\right)$.

The amount of (gr) of dry adsorbent obtained is calculated with equation (4).

$$
P_{a s}=P_{t}-P_{m}
$$

In the container with water at $0^{\circ} \mathrm{C}$ the Erlenmeyer with the dry and heavy adsorbent is placed, this communicates with another Erlenmeyer with the same structure of the stopper and glass valve; but with the adsorbate anhydrous, in an amount that covers half of the Erlenmeyer, as shown in figure 3, the installation for saturation.

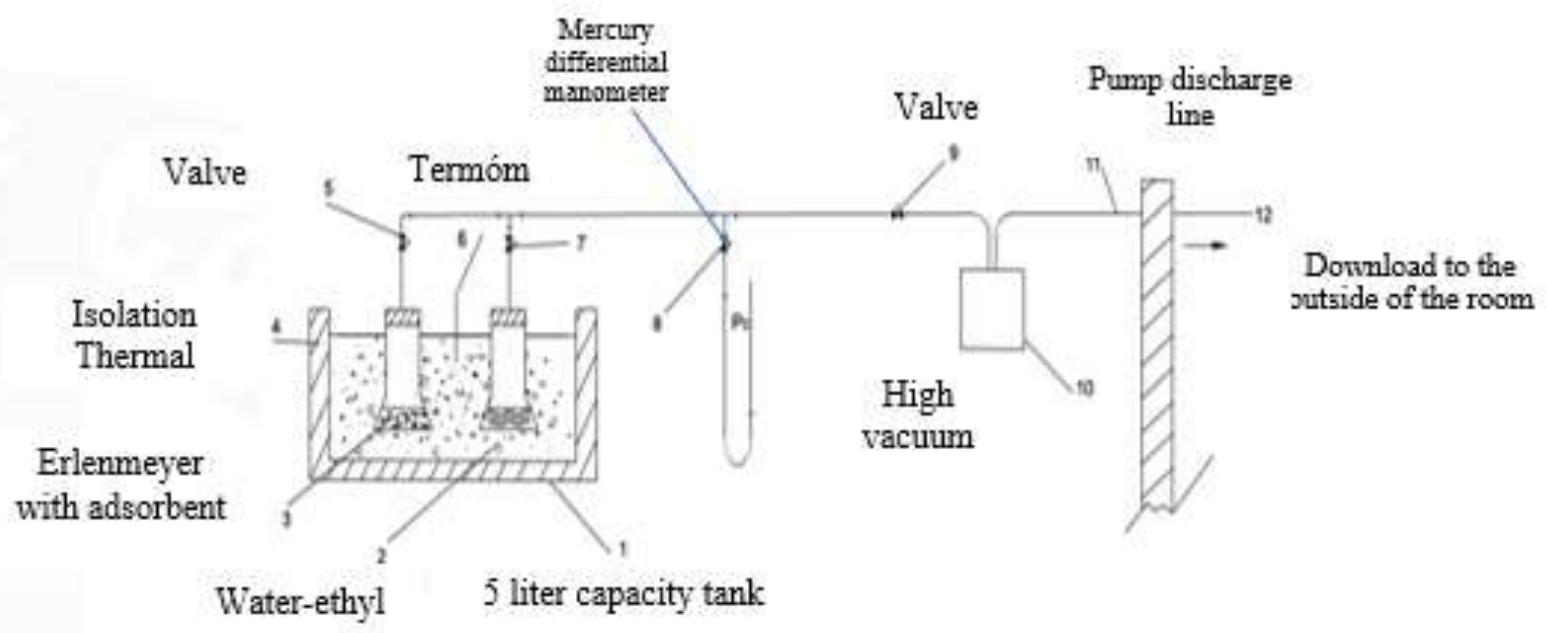

Figure 3. Installation for saturation

The connections between the Erlenmeyer, the differential manometer and the vacuum pump, are made by means of 6 $\mathrm{mm}$ diameter copper tubing and rubber hose. To perform the saturation operation, the pump 10 is put into operation, slowly opening the valve 9 and the valve 8 of the differential manometer to avoid mercury entrainment, in this case, a mercury trap can be placed to avoid accidents. Next, valve 5 is opened, the air is evacuated from the Erlenmeyer, valve 5 is closed and the 7 is opened, evacuating the Erlenmeyer gases with the adsorbate. For this reason, the discharge of the pump must be outside to avoid the toxic gases of certain adsorbed.

The evacuation of air and gases from the lines and Erlenmeyer is carried out, valve 9 is closed and valve 8 is opened and valve 7 is opened. In this circumstance, the differential manometer will indicate a level of mercury that marks the pressure of the adsorption to the temperature $0^{\circ} \mathrm{C}$. Then valve 5 is opened so that the column of mercury in the manometer will rise. This indicates that the adsorbent contained in the Erlenmeyer 3 is absorbing. The adsorption will continue until the column of mercury returns to the initial level. P_0. The installation must guarantee tightness so it must be tested before the tests to avoid infiltration of air. The saturation operation can last from 1 to 4 hours it is necessary that the external container should always be kept at the temperature of $0^{\circ} \mathrm{C}$.

The absorbent is considered saturated when opening and closing the valve 5, no variation in the mercury column is observed. The valves then closed 5, 7 and 8 are and the Erlenmeyer 3 is disconnected from its stopper and valve (5), dried and the assembly weighed. This measurement (Ps) is the gross weight with the saturated adsorbent. 
Then:

$$
P_{s}-P_{t}=\text { Absorb weight }(\mathrm{gr})
$$

The saturation concentration can be calculated by equation

$$
M_{B}=\frac{P_{s}-P_{t}}{P_{a s}} * 100(\text { adsorbate } g r) /(\text { Kg of }) \text { adsorbent }
$$

Where:

$\mathrm{M}_{\mathrm{B}} \rightarrow$ Saturation concentration. Point $\mathrm{B}$ is shown in figure 1.

Then the installation must be transformed according to figure 4 .

nomenclature:

Thermostatic bath (1), water (2), electrical resistance of the bath (3), bath remover (4), Erlenmeyer with saturated adsorbent (6), outside air intake valve (7), differential pressure gauge valve (9), differential pressure gauge (10), valve (11), vacuum pump (12), outside (13) ).

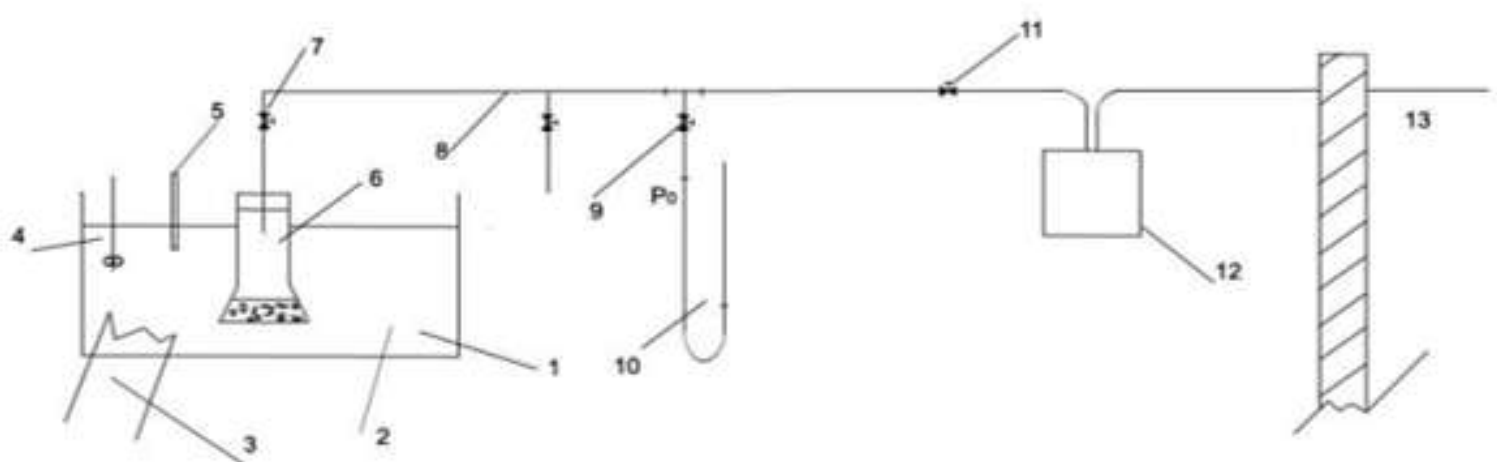

Figure 4. Installation to determine M_D

The transformation of the installation consists of using a thermostatic bath that allows regulating the temperature from $t_{m a}$ to $T_{p}$. For this, the Erlenmeyer with the adsorbate is removed see figure 3 leaving the valve 8 (figure 4 ) to the outside. The rest of the installation remains the same as in figure 3.

The Erlenmeyer with the saturated adsorbent is now placed inside the thermostatic bath, which is at the temperature tma, with the valve (7) closed, the (9) closed and (11) open, then the pump is started (12) It slowly opens 9 to avoid the mercury drag of 10 . With the opening of 8 , air is allowed to enter the system, regulating until the mercury column takes the height $P_{0}$ previously marked. When the saturated adsorbent found in (6) reaches a bath temperature, with pump 12 running and $P_{0} \mathrm{P}_{\mathrm{t}}$ fixed valve (7) is opened and all the adsorbate is discharged that does not admit the adsorbent until reaching the point D shown in figure 1 . This operation takes approximately 15 to 20 minutes; then the valves (7) and (11) are closed and the Erlenmeyer (6) is removed, dried, and weighed, this weight is $\mathrm{P}_{1}$.

Then:

$$
\begin{aligned}
& P_{1}-P_{t}=\text { Weight adsorbate }(\mathrm{gr}) \\
& M_{D}=\frac{P_{s}-P_{t}}{P_{a s}} * 100(\text { adsorbate } g r) /(K g \text { of }) \text { adsorbent }(7)
\end{aligned}
$$

Escobar, B. B., \& Gordin, R. G. (2018). Experimental method to determine the isosteres of adsorbent/adsorption pairs of adsorption cooling systems. International Research Journal of Engineering,

IT \& Scientific Research, 4(6), 1-9. https://doi.org/10.21744/irjeis.v4n6.330 
This value gives the maximum concentration under the conditions imposed to the cycle studied. In the same system shown in Figure 4 the bath temperature is regulated $t_{p}$ is searched for manual absolute pressure in $\mathrm{mm}$ mercury adsorbate at the temperature $\mathrm{t}_{\mathrm{k}}$, it is looked for in manuals and not as it was done to determine $\mathrm{Pt}$, because tk is always higher than the ambient temperature and the absorbing vapors that are extracted from the Erlenmeyer will condense in the connection pipe and can affect the column of mercury giving a false value.

It is then convenient to have an anhydrous adsorbate, and a barometer to determine the atmospheric pressure during the test.

Here;

$\mathrm{Pk} \rightarrow$ gauge pressure in $\mathrm{mm} \mathrm{Hg}$.

$\mathrm{Pak} \rightarrow$ absolute pressure is given in the manual $\mathrm{mm} \mathrm{Hg}$.

$\mathrm{Pat} \rightarrow$ atmospheric pressure in $\mathrm{mm} \mathrm{Hg}$.

It would be then the equation (8), where:

$$
P_{k}=P_{a t}-P_{a k}
$$

This $\mathrm{P}_{\mathrm{k}} \mathrm{kPk}$ is marked on the differential column and proceeds as follows:

The Erlenmeyer (6) (see figure 4) is placed inside the thermostatic bath that is at the temperature tp, with the valve (7). When the vacuum pump (12) is closed, the valve (11) is opened and the valve (8) is slowly opened until the mercury column is at the height that characterizes the pressure $\mathrm{Pk}$.

When these conditions are met, valve (7) of figure 4 is opened and all the excess adsorbate is expelled.

This operation lasts from 15 to 20 minutes. The valve (7) and (11) are closed and the vacuum pump (12) is switched off. The saturated adsorbent (6) is then dried and weighed, resulting in P2.

Then:

$P_{2}-P_{t}=g$ Adsorbate

Then obtained MH shown in equation (9)

$M_{H}=\frac{P_{2}-P_{t}}{P_{a s}} * 100($ adsorbate $\mathrm{gr}) /(\mathrm{Kg}$ of $)$ adsorbent

\section{Results and Discussions}

The main result obtained is the amount of absorption that the adsorbent manages to adsorb and desorb at the temperatures that are established as conditions for the design of a cooling installation, this value is the difference of M_D-M_H which is the value of adsorption-desorption required for the design of such systems. Because the characteristics of the commonly used adsorbents (zeolite, activated carbons, etc.) are very varied, the preparation of isosteres would be a long and expensive task when using methods indicated in the specialized literature. This method is not intended to be exact quantitative but qualitative, its accuracy will depend on the characteristics of the instruments used for the measurements made in the experiments.

\section{Conclusion}

The results obtained for different pairs in different operating conditions, allow selecting the most suitable for the desired cooling purposes, considering the temperature levels that can be reached in correspondence with the energy source that will be used. The method described allows from the values $M_{D}-M_{H}$ that are obtained, and from the refrigeration capacity that it is desired to obtain in a defined facility, that the amount of refrigerant and adsorbent necessary to achieve said capacity can be determined. 
Conflict of interest statement and funding sources

The authors declared that they have no competing interest. The study was financed by personal funding.

Statement of authorship

The authors have a responsibility for the conception and design of the study. The authors have approved the final article.

\section{Acknowledgments}

Thank the Catholic University of Santiago de Guayaquil and Dr. María Rodríguez Gámez from the Technical University of Manabí, for their support for the publication of this article.

Escobar, B. B., \& Gordin, R. G. (2018). Experimental method to determine the isosteres of adsorbent/adsorption pairs of adsorption cooling systems. International Research Journal of Engineering, IT \& Scientific Research, 4(6), 1-9. https://doi.org/10.21744/irjeis.v4n6.330 


\section{References}

Allouhi, A., Kousksou, T., Jamil, A., Agrouaz, Y., Bouhal, T., Saidur, R., \& Benbassou, A. (2016). Performance evaluation of solar adsorption cooling systems for vaccine preservation in Sub-Saharan Africa. Applied Energy, 170, 232-241.

Brossard L F., Guillén R J., Vázquez L C. (1993). Qualitative method for the determination of the absorbentdesorbent possibilities of adsorption pairs. Ibero-American Conference on Technical Sciences. ISPJAM. Stgo of Cuba.

González, M. I., Rodríguez, L. R., \& Lucio, J. H. (2009). Evaluation of thermal parameters and simulation of a solarpowered, solid-sorption chiller with a CPC collector. Renewable energy, 34(3), 570-577.

Rodriguez, A. C. Z., Gamez, M. R., \& Faure, L. G. (2018). Design, construction, and energy of sustainable solar dryers in Jipijapa Canton. International Journal of Physical Sciences and Engineering, 2(2), 88-100.

Sadhikh, M., \& Skaria, J. J. (2016). Development of Waste Heat Fired Activated Carbon Ammonia Adsorption Chiller. International Journal of Thermal and Environmental Engineering, 11, 131-135.

Sataralli A. et al (2012). Method for the determination of adsorption parameters of the methanol-activated carbon pair used in solar cooling systems. Advances in Renewable Energy and the Environment Vol. 16. Printed in Argentina. ISSN 0329-5184.

Shmroukh, A. N., Ali, A. H. H., Abel-Rahman, A. K., \& Ookwara, S. (2015). Experimental Investigation on Adsorption Capacity of a Variety of Activated Carbon/Refrigerant Pairs. Int. Journal of Engineering Research and Application, 5(4), 66-76. 


\section{Biography of Authors}

\begin{tabular}{|l|l|}
\hline \hline & Bohórquez, \\
Computer Systems Engineer, Master in Telecommunications, Senior Professor, Faculty \\
of Technical Education for Development, Catholic University of Santiago de \\
Guayaquil. Director of Master in Electricity with a specialization in Renewable Energy \\
and Energy Efficiency. Principal Representative of the professors before the Board of \\
Directors of the Faculty of Technical Education for the Development of the University. \\
Email: bbohorquez52@hotmail.es \\
\hline
\end{tabular}

Escobar, B. B., \& Gordin, R. G. (2018). Experimental method to determine the isosteres of adsorbent/adsorption pairs of adsorption cooling systems. International Research Journal of Engineering, IT \& Scientific Research, 4(6), 1-9. https://doi.org/10.21744/irjeis.v4n6.330 